\title{
TRAJETÓRIAS BASILARES EM DIREÇÃO A UM MODELO DE UNIVERSIDADE EMPREENDEDORA
}

\author{
FÁBIO DAL-SOTO ${ }^{1}$ \\ ORCID: https://orcid.org/0000-0002-0342-2706 \\ YEDA SWIRSKI DE SOUZA ${ }^{2}$ \\ ORCID: https://orcid.org/0000-0001-9299-9509 \\ MATS BENNER ${ }^{3}$ \\ ORCID: https://orcid.org/0000-0003-3446-9344
}

\begin{abstract}
RESUMO: O fenômeno da universidade empreendedora tem sido tema de importante debate e discussão em diferentes contextos econômicos e sociais, devido à necessidade de maior interação entre universidade, indústria e governo. Em função disso, várias universidades em diversas partes do mundo têm se engajado em um processo de transformação em direção a um novo modelo organizacional, com aderência a uma universidade mais empreendedora ou inovadora. Nesse contexto, esta pesquisa tem o objetivo de analisar a trajetória percorrida pelas universidades estudadas em busca de um modelo de universidade empreendedora. Para isso, a técnica de estudo de casos múltiplos foi utilizada, tendo como campo empírico três universidades: duas no Brasil, a Pontifícia Universidade Católica do Rio Grande do Sul (PUCRS) e a Pontifícia Universidade Católica do Rio de Janeiro (PUC-Rio), e uma na Suécia, a Lund University (LU). Os resultados mostram que as universidades pesquisadas desenvolveram trajetórias baseadas nas atividades de pesquisa, as quais contribuíram significativamente para o incremento nas relações universidade-indústria-governo. Ao mesmo tempo, os três casos estudados evidenciam a importância da relação estreita com seu entorno de atuação na implementação da terceira missão acadêmica.
\end{abstract}

Palavras-chave: universidade empreendedora, terceira missão acadêmica, universidade-indústriagoverno.

\section{BASILAR PATHWAYS TOWARDS AN ENTREPRENEURIAL UNIVERSITY MODEL}

\footnotetext{
${ }^{1}$ University of Cruz Alta (Unicruz). Cruz Alta, RS, Brazil. < fsoto@unicruz.edu.br>

2 Unisinos Business School (Unisinos). Porto Alegre, RS, Brazil. <yedasou@unisinos.br>

${ }^{3}$ Lund University. Lund, Skåne, Sweden. <mats.benner@ehl.lu.se>

ABSTRACT: The phenomenon of the entrepreneurial university has been the subject of important debates and discussions in different economic and social contexts due to the need for greater interaction between university, industry, and government. As a result, several universities in different parts of the world have been engaged in a transformation process towards a new organizational model, with adherence to a more entrepreneurial or innovative university. In this context, the aim of this study is to 
analyze the pathways developed by studied universities pursuing an entrepreneurial university model. Therefore, the technique of multiple case study was used having three universities as the empirical field: two in Brazil, the Pontifical Catholic University of Rio Grande do Sul (PUCRS) and the Pontifical Catholic University of Rio de Janeiro (PUC-Rio), and one in Sweden, Lund University (LU). Results show that those universities developed pathways based on research activities, which significantly contributed to the increase of university-industry-government relationships. In addition, the three cases show the relevance of a close relationship with their surroundings when implementing the third academic mission.

Keywords: entrepreneurial university, third academic mission, university-industry-government.

\section{TRAYECTORIAS BASILARES HACIA UN MODELO DE UNIVERSIDAD EMPRENDEDORA}

RESUMEN: El fenómeno de la universidad emprendedora ha sido objeto de importantes debates y discusiones en diferentes contextos económicos y sociales, debido a la necesidad de una mayor interacción entre la universidad, la industria y el gobierno. Como resultado, varias universidades en diferentes partes del mundo han participado en un proceso de transformación hacia un nuevo modelo organizacional, con adhesión a una universidad más emprendedora o innovadora. En este contexto, esta investigación tiene como objetivo analizar la trayectoria seguida por las universidades estudiadas en busca de un modelo de universidad emprendedora. Para esto, se utilizó la técnica de estudio de caso múltiple, teniendo como campo empírico tres universidades: dos en Brasil, la Pontificia Universidad Católica del Rio Grande do Sul (PUCRS) y la Pontificia Universidad Católica del Rio de Janeiro (PUC-Río) y uno en Suecia, Universidad de Lund (LU). Los resultados muestran que las universidades investigadas desarrollaron trayectorias basadas en actividades de investigación, que contribuyeron significativamente al aumento de las relaciones universidad-industria-gobierno. Al mismo tiempo, los tres casos estudiados muestran la importancia de la estrecha relación con su entorno en la implementación de la tercera misión académica.

Palabras clave: universidad emprendedora, tercera misión académica, universidad-industria-gobierno. 


\section{INTRODUÇÃO}

A dinâmica ambiental instiga as universidades a terem maior aproximação com a sociedade como um todo. Esse desafio é histórico e está diretamente relacionado aos diferentes modelos assumidos pelas universidades em diversos lugares do mundo. A fim de atender as alterações ambientais e de interferir na própria dinâmica ambiental, as universidades movimentam-se em direção a novos modelos, com destaque para o da universidade empreendedora ou inovadora, o qual vem sendo utilizado em diferentes contextos econômicos e sociais.

À medida que o conhecimento assume parcela cada vez mais importante na inovação, o papel da universidade, como instituição de produção e disseminação do conhecimento, se reveste de maior significado no processo de inovação industrial. Além do estabelecimento de vínculos com outras organizações existentes, a universidade empreendedora desenvolve capacidades para auxiliar na criação de novas organizações, como a formação de empresas baseadas na pesquisa acadêmica e a liderança na estruturação de organizações regionais (ETZKOWITZ et al., 2000).

Ao assumir um novo papel na sociedade, a universidade passa por mudanças internas, integrando novas funções e relações. Assim, a lógica interna da missão acadêmica original amplia-se através da conservação do conhecimento (educação), seguida da criação de conhecimento (pesquisa) e pela aplicação deste novo conhecimento (empreendedorismo) (ETZKOWITZ, 2013a). Nesse sentido, assume-se, como pressuposto, que as mudanças realizadas no âmbito das universidades estudadas têm como norteadora a transição de um modelo de universidade híbrida, humboldtiano ou tradicional, calcado no ensino e na pesquisa, para uma universidade mais engajada e empreendedora, a exemplo do indicado por Tijssen (2006) e como proposto por Clark (1998, 2004) e Etzkowitz (2013a, 2013b).

É nesse lócus que esta pesquisa se insere, com base na seguinte indagação: como as trajetórias desenvolvidas pelas universidades têm possibilitado a transformação institucional em direção a um modelo de universidade empreendedora? A partir disso, o objetivo desta pesquisa consiste em analisar a trajetória percorrida pelas universidades estudadas em busca de um modelo de universidade empreendedora.

Em geral, os modelos globais em torno da temática da universidade empreendedora são frequentemente associados a determinados atributos organizacionais, sem o reconhecimento da interrelação entre as capacidades e características institucionais e as do ambiente externo, no qual a universidade está inserida (STENSAKER; BENNER, 2013). Além disso, os modelos tradicionais de universidades, como o humboldtiano, o napoleônico e o anglo-saxão, não são suficientes para explicar as transformações de uma instituição secular, arraigada em missões sólidas, que pode incorporar um papel primário na geração de crescimento econômico regional, em uma sociedade baseada no conhecimento.

Assim, o intento de tornar-se uma universidade empreendedora é explorado por Clark (1998) e Etzkowitz (2013b) como uma alternativa para os inúmeros problemas apresentados pelo contexto globalizado, dinâmico e competitivo e pelas próprias trajetórias desenvolvidas pelas universidades, como a falta de eficiência, de diversificação de receita e de relevância para a sociedade. A busca de novos comportamentos organizacionais implica em uma variedade de estratégias implementadas pelas universidades, delineadas pelos papeis díspares e complexos que desempenham em diversas economias.

Em relação ao campo empírico, as trajetórias desenvolvidas por universidades em uma economia emergente (Brasil) e uma economia avançada (Suécia) são exploradas, por meio de um estudo de casos múltiplos, com foco no processo de transformação de universidades tradicionais em direção a um modelo de universidade empreendedora. As trajetórias evidenciadas, muitas delas antecessoras aos mecanismos e ações iniciais estabelecidos pelas universidades estudadas em direção a um modelo de universidade empreendedora, estabeleceram as condições basilares que viabilizaram esse processo de transformação.

Expostos os argumentos iniciais da pesquisa, a seção a seguir apresenta a literatura acerca da universidade empreendedora. $\mathrm{Na}$ sequência, os procedimentos metodológicos da pesquisa são apresentados, baseados no uso da técnica de estudo de casos múltiplos e nas formas de coleta e análise dos dados. Por conseguinte, as trajetórias dos três casos estudados são apresentadas e discutidas, de forma individualizada e cruzada, e, por fim, as considerações finais são expostas. 


\section{UNIVERSIDADE EMPREENDEDORA}

A literatura sobre universidade empreendedora evidencia vários modelos de transformação da universidade tradicional, como os de Clark (1998, 2004), Etzkowitz (2003a) e Etzkowitz et al. (2000), Nelles e Vorley (2010a) e Rothaermel, Agung e Jiang (2007). Os modelos de Etzkowitz e de Clark são considerados seminais na área, sendo especialmente mencionados na academia, com destaque para o trabalho precursor de Etzkowitz (1983) sobre o papel do cientista empreendedor e da universidade empreendedora, no contexto americano.

O modelo de Etzkowitz fundamenta-se nas interações entre universidades, empresas e governos e seus vários papéis na inovação, formando a denominada hélice tríplice. Nesse modelo, as esferas institucionais podem assumir o papel de outros atores nas interações da hélice tríplice, embora mantenham seus papéis originais e suas identidades distintas. A hélice tríplice atua como uma plataforma para a formação de instituições e a criação de novos formatos organizacionais híbridos para promover a inovação, como uma síntese de seus elementos (ETZKOWITZ, 2003a; ETZKOWITZ et al., 2000).

$\mathrm{Na}$ abordagem da hélice tríplice, a universidade possui papel fundamental como fonte de empreendedorismo, tecnologia e investigações críticas. Nesse enfoque, as universidades empreendedoras têm papel-chave, por meio da transferência de tecnologia, da incubação de novas empresas e da condução de esforços nas renovações regionais. Assim indaga-se: estará a universidade perdendo seu papel tradicional e sua independência, ao se tornar mais intimamente envolvida com a indústria e o governo? Ou estará obtendo um grau mais alto de status e de influência na sociedade, aumentando sua independência, ao assumir um papel mais central na sociedade, por meio de sua contribuição para a inovação? (ETZKOWITZ, 2013a).

Embora essas questões possam gerar interessante debate, o fato é que a capitalização do conhecimento está no cerne de uma nova missão para a universidade, com o objetivo de conectar-se de forma mais próxima aos usuários do conhecimento e estabelecer-se como ator econômico por mérito próprio (ETZKOWITZ, 1998). Esse conceito de universidade empreendedora prevê uma função e uma estrutura acadêmica que são revisadas por meio do alinhamento do desenvolvimento econômico às missões acadêmicas de ensino e pesquisa (ETZKOWITZ et al., 2000).

O modelo proposto por Etzkowitz tem avançado para a denominada "quádrupla hélice", a qual adiciona a sociedade civil como quarto elemento do sistema de inovação. Os argumentos utilizados para a inclusão deste novo elemento residem, fundamentalmente, no fato de que a estrutura da hélice tríplice não é suficiente para o crescimento da inovação no longo prazo e na importância de integrar a perspectiva dos cidadãos em geral. Nessa ótica, a inovação é resultado da cocriação entre empresas, cidadãos, universidades e governo, em um contexto marcado pela existência de parcerias, redes de colaboração e relações simbióticas (AFONSO; MONTEIRO; THOMPSON, 2012).

Ao avançar para o modelo da hélice quádrupla, os usuários finais são posicionados ao lado de universidades, governo e indústria, sinalizando a necessidade de adoção de modos de inovação mais abertos (CARAYANNIS; CAMPBELL, 2012), em que o papel fundamental desempenhado pelas universidades neste sistema é reafirmado. Contudo, há ainda um número limitado de estudos que exploram modelos de inovação e engajamento baseados na hélice quádrupla, o que reflete a natureza emergente do tema (ALEXANDER; MILLER; FIELDING, 2015).

Os avanços do modelo contemplam ainda o surgimento da hélice quíntupla, a qual contextualiza os modelos anteriores e aborda a perspectiva dos ambientes naturais da sociedade e da economia para a produção do conhecimento e os sistemas de inovação. O modelo da hélice quíntupla enfatiza que esses ambientes naturais devem ser caracterizados como condutores para o avanço da produção de conhecimento e dos sistemas de inovação. Ambos os modelos, da hélice quádrupla e da hélice quíntupla, moldam e ampliam os princípios de inovação e conhecimento da hélice tríplice (CARAYANNIS; CAMPBELL, 2012).

Em paralelo a esses avanços, o modelo de Clark $(1998,2004)$ assenta-se na análise de alguns casos de universidades que adotaram posturas extremamente proativas em seus esforços para reformar sua configuração. Os principais casos estudados por Clark são de universidades europeias, como a Universidade de Warwick, na região central da Inglaterra; a Universidade de Twente, no leste da Holanda; 
a Universidade de Strathclyde, em Glasgow, Escócia; a Universidade de Joensuu, na região rural da Finlândia; a Universidade Tecnológica de Chalmers, em Gotemburgo, Suécia.

As evidências acerca das cinco universidades pesquisadas mostram que elas se tornaram mais adaptativas às demandas impostas pelo ambiente externo. A universidade empreendedora incentiva projetos cooperativos empreendedores que envolvem unidades acadêmicas ou departamentos de diferentes áreas do conhecimento, com foco no entorno da universidade (CLARK, 1998).

O ponto central deste modelo reside em mudanças na estrutura e na cultura das instituições que se somam a um caráter organizacional geral (substancialmente revisado ou novo) e não em pequenas mudanças em programas de ensino e pesquisa que se tornam enclaves isolados. O empreendedorismo em questão não é uma postura de gestão restrita a novos empreendimentos de ciência e tecnologia, mas uma ação que opera em toda a universidade, inclusive na proteção dos campos tradicionais de conhecimento necessários para uma competência de alto nível. Além de fundamentar novas bases para a colegialidade e a autonomia, a transformação empreendedora estabelece novos alicerces para a relação sustentável entre os diversos campos de pesquisa, ensino e aprendizagem dos estudantes, inerentes a uma universidade específica (CLARK, 2001).

Apesar das diferentes abordagens e de não haver um caminho único, esses modelos possuem similaridades no processo de transformação da universidade, como a obtenção de fontes variadas de renda, a postura empreendedora da instituição, especialmente dos gestores e pesquisadores, e o impacto no desenvolvimento regional. É notório que o paradigma acadêmico empreendedor possui componentes tanto normativos quanto analíticos (ETZKOWITZ et al., 2000).

No entanto, é sensato considerar que nem todas as universidades se encaixam em um modelo de universidade empreendedora (ETZKOWITZ, 2013a; ETZKOWITZ; KLOFSTEN, 2005; PHILPOTT et al., 2011). Há universidades que se concentram primariamente no ensino ou na pesquisa, e não estão interessadas na comercialização de descobertas científicas e tampouco na participação em esquemas para a melhoria social. Contudo, há um movimento global em direção à transformação das universidades acadêmicas de vários tipos em universidades empreendedoras (ETZKOWITZ, 2013a).

Ressalta-se que a universidade deve reconhecer que os movimentos realizados em direção a um modelo de universidade empreendedora variam de acordo com as experiências e os pontos fortes de cada instituição (PHILPOT'T et al., 2011). A busca pelo ideal da universidade empreendedora deve evitar a adoção de um caminho "one siže fits all" (CLARK, 2001). Ou seja, a capacidade de uma universidade se engajar de forma efetiva em atividades empreendedoras é dependente de seus recursos e de seu contexto de atuação (PHILPOTT et al., 2011; WILLIAMS; KITAEV, 2005).

Isso se ampara no fato de que a atividade da educação superior não é uniforme, pois há diferenças significativas entre sistemas de educação superior de diferentes países e mesmo entre instituições pertencentes ao mesmo sistema educacional (PHILPOT'T et al., 2011). Essas diferenças estão representadas de diversas formas, durante o desenvolvimento histórico do ensino superior, como no nascedouro das atividades acadêmicas empreendedoras de forma bottom-up e top-down, nos contextos americano e europeu, respectivamente, e na implementação das land-grant universities e das clássicas universidades "torre de marfim", no contexto americano (ETZKOWITZ, 2003b).

No âmbito de países emergentes, como o Brasil, o empreendedorismo acadêmico tem adotado um formato mais amplo, no sentido de abarcar significativos problemas sociais, além das questões econômicas. O conceito de incubadoras foi transferido do formato de desenvolvimento de empresas de alta tecnologia para iniciativas de cooperativas de serviços de baixa tecnologia, com o aproveitamento da expertise organizacional desenvolvida no projeto inicial para tratar as profundas desigualdades endêmicas da sociedade brasileira (ETZKOWITZ, 2013b). O empreendedorismo acadêmico tem sido transferido para a população brasileira em geral por meio de cooperativas populares e de outros programas sociais originados na universidade (ALMEIDA; MELLO; ETZKOWITZ, 2012). A universidade empreendedora inclui, portanto, o empreendedorismo social e a geração de movimentos sociais como produtos acadêmicos (ETZKOWITZ, 2013b).

O desenvolvimento de uma universidade empreendedora frequentemente depende de fatores externos à academia, tais como características específicas da indústria e do setor público e das relações entre indústria, universidade e setor público. O empreendedorismo não é uma rota disponível para todas as universidades, mas repousa em redes eficazes e engenhosas que não estão prontamente 
disponíveis para todas as instituições (STENSAKER; BENNER, 2013). Expostos os pressupostos teóricos acerca do temário, a próxima seção apresenta os procedimentos metodológicos que orientaram a investigação.

\section{MÉTODO}

Esta pesquisa está centrada em um estudo de casos múltiplos. A técnica de estudo de caso é utilizada para compreender um fenômeno complexo e dependente do contexto (EISENHARDT, 1989; YIN, 2010) e deve ser escolhida para se examinarem acontecimentos contemporâneos, mas sem a manipulação de comportamentos relevantes. O estudo de caso caracteriza-se por questões de pesquisa do tipo "como" e baseia-se em várias fontes de evidências (YIN, 2010), como realizado nesta investigação.

O objetivo do estudo de caso é a descrição precisa ou a reconstrução de um caso (FLICK, 2009). Um caso conota um fenômeno espacialmente delimitado (uma unidade), observado em um único ponto do tempo ou durante um período de tempo, e compreende o tipo de fenômeno que uma inferência tenta explicar (GERRING, 2007). Especialmente em relação ao estudo de casos múltiplos, a utilização de tal estratégia de pesquisa é aderente em função de as evidências resultantes desse tipo de projeto serem consideradas mais convincentes e de o estudo como um todo ser visto, por conseguinte, como mais robusto (EISENHARDT; GRAEBNER, 2007; HERRIOTT; FIRESTONE, 1983).

Ancorados na estratégia de pesquisa delineada por meio de estudo de casos múltiplos, três casos foram pesquisados: dois no Brasil e um na Suécia. No domínio brasileiro, as duas universidades pesquisadas foram a Pontifícia Universidade Católica do Rio Grande do Sul (PUCRS) e a Pontifícia Universidade Católica do Rio de Janeiro (PUC-Rio). O Tecnopuc, Parque Científico e Tecnológico da PUCRS, foi eleito duas vezes o melhor parque tecnológico do país, em 2016 e em 2009. A Raiar, incubadora de empresas da PUCRS, foi eleita, em 2014, como a melhor incubadora do país de empresas orientadas para a geração e uso intensivo de tecnologias, pela Associação Nacional de Entidades Promotoras de Empreendimentos Inovadores (Anprotec, 2019).

No caso da PUC-Rio, o indicador mais saliente e também objeto deste estudo refere-se à capacidade de captação de recursos da indústria, ocupando a $18^{a}$ posição entre as universidades de todo o mundo, de acordo com o ranking 2018 da Times Higher Education (TIMES HIGHER EDUCATION [THE], 2017). Cerca de 50\% das receitas da instituição são originadas de projetos de pesquisa e colaboração com empresas e governo (AGÊNCIA PUC-RIO DE INOVAÇÃO [AG], 2016), o que é atípico no contexto brasileiro. Além disso, a incubadora da PUC-Rio, o Instituto Gênesis, foi classificada entre as melhores incubadoras do mundo, ocupando a $1^{\mathrm{a}}$ posição na América Latina e a $13^{\mathrm{a}}$ no mundo, de acordo com o ranking sueco UBI Global 2015 (PUC-Rio, 2019).

Em território sueco, o caso da Lund University (LU) foi pesquisado. A LU é a $4^{a}$ instituição sueca no indicador específico sobre a obtenção de receita proveniente da indústria, no ranking 2018 da THE (THE, 2017), o que retrata sua capacidade de transferência de conhecimento. Ela está vinculada ao Ideon Science Park na cidade de Lund, reconhecido como um dos maiores parques tecnológicos europeus e o principal centro de capacitação de recursos humanos advindos da LU (MINISTÉRIO DE CIÊNCIA, TECNOLOGIA E INOVAÇÃO [MCTI], 2015). O Ideon foi fundado, em 1983, através da colaboração entre a própria universidade, o município de Lund e a empresa Wihlborgs Fastigheter AB, constituindo-se como o primeiro parque tecnológico na Suécia e o segundo instalado na Europa, após Cambridge, em 1973 (FEHRMAN; WESTLING; BLOMQVIST, 2005; KAISERFELD, 2017; STAAF, 2016).

Para a coleta de dados, o presente estudo utilizou-se de diferentes procedimentos, classificados em fontes primárias e fontes secundárias. Como fontes primárias, entrevistas in loco foram realizadas com os principais envolvidos na implementação da orientação empreendedora nas universidades pesquisadas, tendo como ponto de partida os membros da direção das universidades e diretores das unidades complementares ou de apoio.

No Brasil, a realização das entrevistas ocorreu no período de janeiro a março de 2017 e, na Suécia, durante o mês de junho do mesmo ano. No primeiro período mencionado, 29 entrevistas foram realizadas, 15 na PUCRS e 14 na PUC-Rio. No segundo período mencionado, 11 entrevistas foram realizadas na LU, incluindo o Ideon, devido à sua estreita colaboração com a LU. A duração de cada 
entrevista variou de 43 minutos a uma hora e 28 minutos, todas foram gravadas, tendo o pesquisador também efetuado anotações. Além dessas fontes primárias, diversos dados secundários foram coletados sobre os casos pesquisados, especialmente através dos websites das IES e de materiais públicos e/ou documentos disponibilizados pelas instituições.

Em relação à análise, dois procedimentos básicos foram adotados na análise dos dados: a análise de conteúdo e a triangulação dos dados. A análise de conteúdo foi utilizada no tratamento dos dados primários, notadamente as entrevistas, as quais foram transcritas na íntegra e analisadas com o auxílio do software NVivo 11.0. A triangulação dos dados foi realizada por meio do cruzamento das informações obtidas de diferentes fontes de dados, incluindo diversos tipos de dados primários e secundários. A adoção desse procedimento proporcionou validade interna da informação, como indicado por Azevedo et al. (2013), pois a utilização de ampla gama de informantes, com experiências e pontos de vista individuais que podem ser comparados, juntamente com o uso de diversos documentos institucionais, contribui para a credibilidade das informações em uma perspectiva qualitativa. Com base nesses procedimentos, a seção a seguir avança para os casos pesquisados, por meio da descrição e análise das trajetórias que condicionaram o processo de transformação nas universidades investigadas.

\section{OS CASOS NO BRASIL E NA SUÉCIA}

Esta seção aborda a trajetória dos três casos pesquisados em busca de um modelo de universidade empreendedora. As distintas trajetórias percorridas pelas universidades em questão são abordadas individualmente e, na sequência, de forma cruzada. Os três casos revelam comportamentos similares e ações particulares, de acordo com o contexto de inserção de cada instituição.

\section{O Caso da PUCRS}

A PUCRS é identificada como uma entidade privada sem fins lucrativos, confessional católica e comunitária, constituída por seu campus em Porto Alegre, capital do estado do Rio Grande do Sul (RS), sul do Brasil, e por uma unidade do seu parque tecnológico (Tecnopuc) localizada em Viamão, na região metropolitana da capital. A cidade de Porto Alegre possui aproximadamente 1,5 milhão de habitantes e sua economia está baseada essencialmente nos setores de serviços e comércio varejista e atacadista (PUCRS, 2019).

Em seu ambiente acadêmico, a PUCRS possui em torno de 30 mil alunos, 1,3 mil professores e 4,7 mil técnico-administrativos, incluindo o Hospital São Lucas. A PUCRS é uma universidade abrangente e oferece 56 opções de cursos na graduação, 24 mestrados e 22 doutorados - organizados em 17 unidades acadêmicas. O Tecnopuc envolve mais de 6,5 mil postos de trabalho e abriga 120 organizações, com a presença de empresas internacionais como Hewlett-Packard, Microsoft, Dell Computer, entre outras (PUCRS, 2019).

A trajetória empreendedora desenvolvida pela PUCRS encontra amparo em suas raízes fundacionais. Constituída no final dos anos 1940, a PUCRS está entre as mais tradicionais IES do Brasil (PUCRS, 2019). Com uma longeva tradição no contexto brasileiro e viés comunitário, a PUCRS atuou, durante a maior parte de sua história, em um ambiente marcado pela dicotomia público-privado promovido pelo sistema nacional de educação superior. Apesar do reconhecimento do modelo comunitário pela Constituição Federal de 1988, a ordem legal, representada pelo Código Civil, pela Lei de Diretrizes e Bases da Educação, pela legislação infraconstitucional e pelos atos administrativos em geral, continuou a reproduzir essa ultrapassada dicotomia na ausência de um marco jurídico apropriado (LAZZARI; KOEHNTOPP; SCHMIDT, 2009), o que, em geral, relegava a PUCRS à condição de instituição privada.

Após longo período nessa condição, somente em 2013 tal disfunção foi corrigida pela Lei no 12.881, a qual define e qualifica as Instituições Comunitárias de Educação Superior (ICES), estabelece suas prerrogativas e finalidades e regulamenta sua cooperação com o Estado (BRASIL, 2013). Embora tendo, de longa data, características comunitárias, a PUCRS foi legalmente reconhecida como ICES apenas em 2014, pela Portaria no 632 da Secretaria de Regulação e Supervisão da Educação Superior do Ministério da Educação (Seres/MEC, 2014a), o que a distingue tanto de IES públicas quanto de IES privadas, especialmente daquelas com agressivas finalidades de lucro. Tal reconhecimento possibilita, 
dentre outros benefícios, o acesso a recursos para pesquisa especificamente destinados para esse tipo de IES, anteriormente destinados, via de regra, estritamente às IES públicas.

Apesar de ser recente o reconhecimento formal, a PUCRS exerceu, ao longo do tempo, inúmeros imbricamentos com a sociedade, por meio de atividades de ensino, pesquisa e extensão, o que proporcionou-lhe enraizamento local, marcado por importantes vínculos com a comunidade local e regional. Entre os preceitos de uma universidade empreendedora, o foco sobre o entorno da universidade é defendido por Clark (1998) para o desenvolvimento de projetos empreendedores que envolvam diversas áreas do conhecimento e diferentes atores.

Amparada em relações sem fins lucrativos e não esporádicas, a PUCRS estabeleceu importantes laços com a comunidade, os quais contribuíram para o desenvolvimento de suas atividades empreendedoras e para o desenvolvimento regional. Isso se evidencia, por exemplo, no "Projeto Porto Alegre Tecnópole", no qual a PUCRS atuou conjuntamente com inúmeros atores locais e regionais, a fim de transformar a realidade da região metropolitana de Porto Alegre.

Essa atuação conjunta proporcionou o surgimento de uma concepção compartilhada entre os participantes do referido projeto, o que foi decisivo para as instalações futuras do Tecnopuc e de outros parques tecnológicos e mecanismos de inovação na região, como o Parque Tecnológico da Unisinos, o Tecnosinos, e o Centro de Excelência em Tecnologia Eletrônica Avançada, o CEITEC (SPOLIDORO; AUDY, 2008). A criação de laços na comunidade local e regional mostra a interação estreita e arraigada universidade-ambiente, bem como a importância da localização da PUCRS, na cidade de Porto Alegre, como lócus de infraestrutura adequada e atrativa para inovação e novos empreendimentos baseados em pesquisa e tecnologia.

\footnotetext{
“[A localização] É fator absolutamente determinante para o sucesso dessas ações, principalmente do Tecnopuc, é o nosso entorno [...]. O ecossistema que nós temos aqui na área de educação superior e de pesquisa, principalmente a UFRGS e a Unisinos, é determinante no sucesso do Tecnopuc, porque essas empresas todas, principalmente as internacionais, quando escolhem e se instalam em um local como esse, elas não estão só preocupadas com o local aonde elas vão. Elas estão preocupadas com que haja um ecossistema de inovação importante." (Entrevistado 8)
}

Como importante hub de conexão entre a universidade e seu ambiente, o Tecnopuc desenvolve suas atividades por meio de mais de uma centena de elos que conectam a PUCRS com empresas, associações, órgãos do governo e sociedade em geral. Além do aproveitamento nas atividades tradicionais de ensino e pesquisa, esses relacionamentos produzem outros impactos, através da geração e da atração de novos empreendimentos, empregos e talentos, como abordado por Guerrero, Cunningham e Urbano (2015), e da formação de empresas baseadas na pesquisa acadêmica, como sustentado por Etzkowitz et al. (2000). Isso se alinha aos argumentos de Etzkowitz (2013a), o qual defende o papel-chave das universidades empreendedoras na transferência de tecnologia, na incubação de novas empresas e nos esforços de renovação regional.

A trajetória da PUCRS também é marcada pelo intenso desenvolvimento da pós-graduação, desde os primeiros programas, iniciados no final dos anos 1960 e início dos anos 1970, como Letras (1969), Cirurgia e Traumatologia Bucomaxilofacial (1969), Educação (1972) e Filosofia (1973), alguns deles pioneiros no contexto nacional. Apesar de essas atividades terem principiado no final dos anos 1960, o contexto da instituição, na década 1980, ainda era marcado pelo baixo percentual de professores com titulação de doutorado. Em 1987, por exemplo, a PUCRS possuía 64 professores com título de doutorado, equivalente a 5\% de seu quadro docente, o que prejudicava sua imagem quando comparada às suas congêneres e ameaçava a consecução das metas institucionais, como a melhoria da qualidade do ensino associada à ampliação e ao avanço da pesquisa científica (SPOLIDORO; AUDY, 2008).

Esse cenário foi radicalmente modificado com o lançamento, em 1988, do programa "Mil mestres e doutores para o ano 2000". Esse programa tinha o objetivo de promover a qualificação dos docentes e estabelecia condições para que, em pouco mais de dez anos, cerca de mil de seus professores obtivessem a titulação de mestrado e doutorado, em diversas áreas do conhecimento. Dentre os estímulos oferecidos, destacava-se a manutenção dos salários dos docentes que realizassem o doutoramento fora do estado do Rio Grande do Sul. A implementação desse programa resultou na 
jornada de centenas de docentes rumo a renomadas universidades, no país e no exterior, para a qualificação em diferentes especialidades (SPOLIDORO; AUDY, 2008).

O referido programa proporcionou o avanço mais amplo e denso da pesquisa e dos programas de pós-graduação na instituição e transformou sua realidade até então calcada nas atividades de ensino. Isso se evidencia nos diversos programas de pós-graduação criados nos anos 1990 e no início dos anos 2000, muitos deles viabilizados pela qualificação do corpo docente, tais como: Medicina e Ciências da Saúde (1993), Teologia (1993), Ciência da Computação (1994), Comunicação Social (1994), Engenharia Elétrica (1994), Medicina Pediatria e Saúde da Criança (1995), Ciências Criminais (1997), Odontologia (1999), Gerontologia Biomédica (2000), Educação em Ciências e Matemática (2001), Engenharia e Tecnologia de Materiais (2001), Economia (2002) e Biologia Celular e Molecular (2003). Além dessas treze novas pós-graduações, constituídas em cerca de dez anos, outros programas anteriormente criados pela PUCRS avançaram, nesse mesmo período, para o nível de doutorado, como Filosofia (1995), Psicologia (1995), Serviço Social (1998) e Direito (2000) (COORDENAÇÃO DE APERFEIÇOAMENTO DE PESSOAL DE NÍVEL SUPERIOR [CAPES], 2017).

\footnotetext{
“Isso [o programa "Mil mestres e doutores para o ano 2000”] na realidade acabou sendo a grande mudança que a gente teve de perfil da Universidade. A Universidade era uma universidade muito focada antes no ensino, basicamente nas questões de ensino. [...] Com essa virada, a gente pode dizer que o Programa promoveu nesse período a experiência [...]. Na verdade, isso permitiu a criação de uma massa critica de pesquisadores na instituição que até então nós não tínhamos, e isso acabou se refletindo em 'n' aspectos. Acabou refletindo em uma pós-graduação mais forte, porque aí começamos a criar novos programas de pós-graduação, e programas de pós-graduação que passaram a ter uma avaliação cada vez mais qualificada com essa formação do corpo docente." (Entrevistado 14)
}

Em pouco mais de uma década, a pós-graduação avançou exponencialmente na PUCRS. Como pesquisa e pós-graduação estão estreitamente relacionadas, por certo essa evolução foi sustentada pelo foco acentuado em atividades de pesquisa. Isso se tornou crucial na transformação institucional, a qual proporcionou o avanço nas relações universidade-empresa-governo baseadas na pesquisa. Portanto, como uma "bola de neve", a transformação da PUCRS em direção a um modelo de universidade empreendedora se consubstancia em um processo cumulativo de ações, iniciado pelo programa "Mil mestres e doutores para o ano 2000" e potencializado pela qualificação das atividades de pesquisa e pós-graduação.

Essa trajetória permitiu à PUCRS alcançar aproximadamente $60 \%$ de seu quadro docente com titulação de doutorado e desenvolver 24 programas de pós-graduação, os quais estão distribuídos em quatro grandes áreas do conhecimento: oito nas ciências da saúde e biológicas; oito nas ciências humanas; cinco nas ciências sociais aplicadas; três nas ciências exatas e tecnológicas (PUCRS, 2019). Na última avaliação realizada pela Coordenação de Aperfeiçoamento de Pessoal de Nível Superior (CAPES), em 2017, 11 desses programas obtiveram conceito 6 ou 7, considerados de excelência internacional, e 10 deles alcançaram conceito 5, considerados de excelência nacional (CAPES, 2017).

Forjadas essas duas importantes bases, pelo comprometimento com o desenvolvimento regional com peculiaridades comunitárias e pela ênfase nas atividades de pesquisa, a PUCRS condicionou-se para o estabelecimento de uma série de ações voltadas ao estímulo do empreendedorismo e à inovação no ambiente acadêmico. Essa transformação concretizou-se a partir da criação da Agência de Gestão Tecnológica da PUCRS (AGT), em 1999, a qual recebeu a missão de gerir o processo de interação universidade-empresa-governo e de promover projetos de pesquisa e desenvolvimento, por meio da reunião das necessidades do mercado e da sociedade com o ensino e a pesquisa da instituição. A criação da AGT representou concretamente o marco de uma nova fase institucional, alinhada à terceira missão da universidade (AUDY; KNEBEL, 2015).

Logo após a criação da AGT, a PUCRS moveu-se literalmente para um novo terreno. $\mathrm{O}$ fato foi a aquisição do terreno até então utilizado pelo $18^{\circ}$ Batalhão de Infantaria Motorizada do Exército Brasileiro, nas adjacências do campus central da universidade. $O$ interesse nessa aquisição vinha de longa data, tendo sido manifestado na década de 1970, mas se concretizou efetivamente apenas em maio de 2001. Não havia qualquer plano para a utilização do local como parque tecnológico, no entanto, ainda em 2001, empresas que há anos desenvolviam projetos cooperados de pesquisa e desenvolvimento com 
a PUCRS, especialmente a Hewlett-Packart e a DELL, expressaram à AGT o interesse na ampliação das atividades no âmbito da universidade. Em meio a uma convergência de fatores internos e externos, iniciou-se aí a utilização de parte do quartel adquirido como um parque tecnológico (SPOLIDORO; AUDY, 2008).

A partir disso, sucessivos atores e mecanismos foram desenvolvidos pela PUCRS na implementação da terceira missão acadêmica, como o Tecnopuc e a incubadora RAIAR, ambos em 2003, o Escritório de Transferência de Tecnologia (ETT), em 2005; o Laboratório de Criatividade do Tecnopuc (CriaLab), em 2011; e o Laboratório Interdisciplinar de Empreendedorismo e Inovação (Idear), em 2016. Articulados na rede INOVAPUCRS, esse conjunto de atores e mecanismos forma um estrutura de difícil replicação e arraigada na própria instituição. Essas características particulares e o enraizamento na própria trajetória encontram subsídio nos trabalhos de O'Shea et al. (2005), Philpott et al. (2011) e Stensaker e Benner (2013). A realização cumulativa dessas ações e o desenvolvimento de mecanismos interdependentes também são defendidos por Clark $(2004,2006)$ na implementação do ideal empreendedor. Expostos os principais marcos e a trajetória desenvolvida pela PUCRS em direção a um modelo de universidade empreendedora, a próxima subseção aborda o segundo caso pesquisado.

\section{O Caso da PUC-Rio}

A PUC-Rio é configurada como uma instituição de direito privado, confessional católica, comunitária, filantrópica, sem fins lucrativos. Seu campus está localizado em meio à exuberante e densa vegetação tropical que caracteriza a cidade do Rio de Janeiro, capital do estado homônimo, localizado na região sudeste do Brasil. O Rio de Janeiro possui aproximadamente 6,5 milhões de habitantes, com sua economia baseada no setor de serviços, constituindo-se em dinâmico centro administrativo, financeiro, comercial e cultural (PUC-Rio, 2019).

Caracterizada em alguns números, a PUC-Rio possui cerca de 22,5 mil alunos, 1,2 mil docentes e 1,8 mil técnico-administrativos, dos quais em torno de 600 estão vinculados a projetos ou convênios. A PUC-Rio dispõe de 40 opções de cursos na graduação, 28 mestrados e 25 doutorados, organizados em quatro centros: Centro de Teologia e Ciências Humanas (CTCH), Centro de Ciências Sociais (CCS), Centro Técnico Científico (CTC) e Centro de Ciências Biológicas e da Saúde (CCBS) (PUC-Rio, 2019).

A orientação empreendedora desenvolvida pela PUC-Rio encontra amplo amparo em suas raízes fundacionais com viés comunitário e em sua extensa trajetória em pesquisa e pós-graduação, no contexto brasileiro. Constituída na década de 1940, a PUC-Rio está entre as mais tradicionais IES do Brasil (PUC-Rio, 2019). Apesar de sua vocação comunitária, ela conviveu, durante maior parte de sua história, no ambiente da educação superior brasileira caracterizado pela dicotomia público-privado, sendo relegada ao conjunto das instituições privadas. Essa disfunção foi corrigida somente em 2013, pela Lei $N^{\circ}$ 12.881, complementada, em 2014, pela Portaria n 679 da Seres/MEC, a qual qualifica e reconhece formalmente a PUC-Rio como universidade comunitária ou pública não estatal (Seres/MEC, 2014b).

Essa disfunção não impedia o desenvolvimento das características comunitárias da PUCRio, mas limitava suas possibilidades de acesso a recursos financeiros disponibilizados pelo governo através de editais específicos, particularmente aqueles para as atividades de pesquisa, antes direcionados somente a instituições públicas. Mesmo assim, a PUC-Rio desenvolveu uma série de imbricamentos com a comunidade local/regional, por meio de projetos e ações diretamente relacionados com o desenvolvimento econômico e social em sua região de atuação, o que é defendido por Clark (1998) como um dos principais aspectos na transformação em direção a um modelo de universidade empreendedora.

A PUC-Rio atua em contexto marcado por peculiaridades que influenciaram seu desenvolvimento e está enraizada nos contrastes advindos de sua localização. De um lado, ela se situa em uma importante região produtiva e econômica do país, que integra o sudeste brasileiro, com a presença de grandes empresas, como a Petrobrás - que atua nas indústrias de óleo, gás natural e energia -, a mineradora Vale, a Telemar e a Embratel, ambas da área de telecomunicações. A cidade do Rio de Janeiro é reconhecida como a segunda maior metrópole do país e como principal destino turístico internacional do Brasil. Por outro lado, a aparente beleza carioca é ofuscada pelo grande número de favelas e pela violência que assola a cidade em geral, o que desafia a atuação da PUC-Rio de forma empreendedora com o consequente reflexo nos âmbitos econômico e social. 


\begin{abstract}
"O que é interessante aqui na Universidade, ele [o espírito empreendedor] não afeta só o aspecto na área tecnológica, de empresas na área tecnológica ou o aspecto da administração. A gente colocou uma nova vertente que é o empreendedor social, um agente social. Então isso, vamos dizer assim, foi incentivado nos alunos, nesses cursos como agentes sociais, atuando dentro da sociedade pra ação social de grupos não privilegiados, e usando o seu conhecimento para melhorar as condições de vida das pessoas. E um outro aspecto do empreendedorismo. Isso foi bastante incentivado na Universidade.” (Entrevistado 25)

\footnotetext{
"Agora, cada dia mais a gente vê a importância da Universidade se abrir para a sociedade, e essa abertura, exatamente, se dá através desses projetos. E aí eu diria pra você o seguinte, claro que não são projetos, óbvio, de base científica, não são, mas são projetos, por exemplo, na área de educação. Aqui no entorno nós temos 10 escolas, aqui no entorno da PUC-Rio. Nós trabalhamos com essas escolas, pessoal de Educação trabalha, pessoal de Letras tem alguns projetos, o Instituto Interdisciplinar de Leitura tem alguns projetos, a Cátedra Unesco tem alguns projetos, porque é a maneira que a gente tem de ter a relação de interface com o entorno, porque eu acho que isso é muito importante, senão a universidade fica em cima de nada." (Entrevistado 23)
}

Além dos diversos elos estabelecidos pela PUC-Rio com a indústria local, como sustentado por Bramwell e Wolfe (2008), ela desenvolve inúmeros projetos de inserção nas comunidades locais/regionais, com foco naquelas que apresentam vulnerabilidade social, com a ideia de empreendedorismo acadêmico adaptado aos problemas sociais, como abordado por Etzkowitz (2013b). Um dos principais exemplos desses imbricamentos com o entorno encontra-se no Instituto Gênesis, o qual possui uma de suas áreas de atuação especificamente voltada para o desenvolvimento local, tanto por meio de projetos de empreendedorismo para comunidades e regiões, como através de mecanismos e metodologias de intervenção que buscam promover a inclusão social. Boa parte dos projetos realizados pelo Instituto Gênesis são desenvolvidos em parceria com o governo e o meio empresarial.

A PUC-Rio também usufrui de longa tradição em pós-graduação no Brasil. De forma arrojada para o período, ela iniciou seu percurso na pós-graduação com a criação de dez programas, todos na década de 1960, vários deles pioneiros no Brasil ou na América Latina, como Engenharia Elétrica (1963), Engenharia Mecânica (1964), Educação (1965), Engenharia Civil (1965), Física (1965), Psicologia (1966), Engenharia de Produção (1967), Informática (1967), Matemática (1969) e Química (1969). O ímpeto inicial consolidou-se com a criação de novos programas e a qualificação daqueles já existentes, o que proporcionou à PUC-Rio alcançar 28 programas de pós-graduação.

Esse avanço da PUC-Rio resultou em significativa qualidade na pesquisa e na pós-graduação. Em 2001, por exemplo, a PUC-Rio foi reconhecida pela CAPES como a instituição com as melhores notas nos cursos de pós-graduação estrito senso no Brasil (PUC-Rio, 2010). Em 2017, na última avaliação realizada pela CAPES, a PUC-Rio obteve conceito 6 ou 7, em sete de seus programas, portanto reconhecidos como excelência internacional, 15 programas obtiveram conceito 5, sendo considerados de excelência nacional (CAPES, 2017). A tradição e a qualidade são suportadas por seu qualificado quadro docente, no qual há cerca de $60 \%$ de professores com titulação de doutorado (PUC-Rio, 2016).

A trajetória singular da PUC-Rio, em pós-graduação, assenta-se em sua capacidade de realização de pesquisa. Com raro impulso, no âmbito das IES comunitárias e privadas, no contexto brasileiro da década de 1960, a PUC-Rio estruturou-se como uma universidade voltada para a pesquisa, como evidencia a qualidade e a quantidade de seus programas de pós-graduação, distribuídos em diversas áreas do conhecimento. Esse modelo foi colocado à prova durante a crise institucional da década de 1990, porém, apesar das dificuldades momentâneas, ficou ainda mais reforçada a trajetória de pesquisa e pós-graduação desenvolvida pela PUC-Rio, especialmente devido à sua capacidade de realização de projetos de pesquisa e na busca de parceiros externos para o custeio dessas atividades.

Até a década de 1990, a PUC-Rio era definida como uma universidade voltada ao ensino e à pesquisa, principalmente teórica. Apoiada por recursos da Financiadora de Estudos e Projetos (FINEP), desde a década de 1960, a PUC-Rio conquistou laboratórios e excelência na pesquisa em ciências exatas e engenharias. No entanto, em 1992, o governo federal realizou algumas mudanças nos investimentos em ciência e tecnologia, retratadas na redução das verbas públicas para a pesquisa científica e no aumento para a área tecnológica. Consequentemente, o financiamento para a PUC-Rio foi drasticamente reduzido e ela foi obrigada a se repensar (GUARANYS, 2006). 
Em resposta a essas mudanças, a PUC-Rio realizou um planejamento estratégico e constituiu o Escritório de Desenvolvimento, em 1994, com o objetivo de estimular a interação com a sociedade, especialmente com as empresas. A equipe dirigente do Escritório de Desenvolvimento concebeu um conjunto de ações para a transformação da universidade e criou, em 1997, o Instituto Gênesis para Inovação e Ação Empreendedora (GUARANYS, 2006). Ao mesmo tempo, os demais institutos já existentes na instituição e seu corpo docente foram "forçados" a repensar suas atividades, especialmente em relação ao financiamento de projetos de pesquisa e ao custeio das horas envolvidas nessas atividades.

As formas encontradas pela PUC-Rio para superar a crise instalada passaram, em boa medida, pelo estreitamento das relações com empresas para o desenvolvimento da pesquisa e a aproximação com a sociedade em geral. A implementação dessas mudanças perpassou as diversas atividades e áreas na Universidade, destacando-se: a) institutos e núcleos de pesquisa; b) Instituto Gênesis, incubadora de empresas da PUC-Rio; c) Empresa Júnior PUC-Rio; d) Agência PUC-Rio de Inovação (AGI). Conjuntamente, esses atores têm mostrado, especialmente por meio de seus institutos de pesquisa, significativa capacidade de captação de recursos para a instituição, os quais perfazem atualmente metade de sua arrecadação.

\footnotetext{
"Em nenhum momento, de todas as crises, a Universidade abandonou o projeto de fazer aqui uma universidade de pesquisa, uma universidade de excelência de pesquisa. No meio daquela crise de não ter o dinheiro para pagar, [...] ainda manteve o projeto de ampliar pesquisa e pós-graduação para todos os departamentos. Em diversos momentos de crises, nunca, nunca deixou, abandonou o projeto de ter aqui e instalar pesquisa e pós-graduação de qualidade em todos os departamentos.” (Entrevistado 20)

\begin{abstract}
"Naturalmente, na construção histórica da instituição, por ser uma instituição privada, ela precisou incentivar os professores ou os próprios professores acharem espaço empreendedor e eles criam e passam a construir algo deles. A Universidade foi construída a partir do desempenho de vários professores, dos docentes. Então, ela precisa ter esse espírito empreendedor, senão não acontece nada. E isso foi motivado, foi valorizado institucionalmente." (Entrevistado 26)
\end{abstract}

A trajetória percorrida pela PUC-Rio é marcada pelo envolvimento do corpo docente com as necessidades institucionais. Especialmente durante a crise da década de 1990, a principal alternativa por ela encontrada consistiu no movimento realizado pelo corpo docente em busca de parceiros externos para a sustentação das atividades de pesquisa e pós-graduação. Essa "saída" revelou o comportamento coletivo e empreendedor do corpo docente, engajado nas principais questões que ameaçavam a continuidade do avanço institucional.

Como resultado desse movimento, a PUC-Rio reforçou significativamente os elos com os parceiros externos, tanto públicos quanto privados, e apostou, com mais veemência, na vertente calcada no empreendedorismo e na inovação que nela aflorava. Baseada em importante amálgama com as atividades de ensino e pesquisa, a nova vertente desenvolvida potencializou as estruturas existentes, especialmente as unidades de pesquisa criadas durante sua trajetória, e gerou novos mecanismos e ações em torno da implementação da terceira missão acadêmica.

A trajetória empreendedora da PUC-Rio está capilarizada em suas unidades de pesquisa, criadas, em boa parte, anteriormente à década de 1990, e baseadas na aproximação de grupos de pesquisa afins. Conjuntamente, esses mecanismos formam o percurso da instituição na busca de maior interação com o governo, as empresas e a sociedade em geral e preenchem a "caixa vazia" da universidade empreendedora, como exposto por Stensaker e Benner (2013). De modo complementar e de acordo com as ideias de Nelles e Vorley (2010b), O’Shea et al. (2005), Philpott et al. (2011) e Stensaker e Benner (2013), o engajamento no intento empreendedor é dependente das capacidades das universidades e dos diferentes acúmulos de recursos, o que realça as peculiaridades de cada organização de acordo com suas trajetórias particulares. Discutidos os principais elementos que condicionaram a transformação da PUCRio em direção a um modelo de universidade empreendedora, a próxima subseção avança para o terceiro caso pesquisado. 


\section{O Caso da LU}

Localizada no condado de Escânia, no sul da Suécia, a LU possui três campi nas seguintes cidades: a) Lund, com 110 mil habitantes, identificada pela presença de empresas de alta tecnologia e como uma cidade universitária, sendo a LU uma das principais empregadoras locais; b) Malmö, situada a $23 \mathrm{~km}$ de Lund, é a terceira maior cidade sueca, com cerca de 340 mil habitantes e evidencia crescente número de empresas nos setores de transporte, serviços financeiros e empresariais, entretenimento, lazer e construção civil; c) Helsingborg, localizada a $55 \mathrm{~km}$ de Lund e com aproximadamente 140 mil habitantes, define-se pela atividade portuária e como um centro regional de comércio, transporte e negócios (LU, 2019).

A LU é uma universidade pública, uma das maiores e mais abrangentes da Suécia, com cerca de 42 mil alunos, dos quais 15\% são estrangeiros. Nela há 7,5 mil funcionários, sendo 800 professores, 4,2 mil pesquisadores e 2,5 mil técnico-administrativos. Os cursos da LU estão organizados em oito faculdades ou escolas: engenharia; ciências sociais; humanidades e teologia; economia e administração; medicina; ciências; direito; belas artes; artes cênicas. Há 80 opções de cursos de graduação e cerca de 100 programas de mestrado (LU, 2019).

A orientação empreendedora desenvolvida pela LU encontra amplo amparo em suas atividades de pesquisa, voltadas para a geração de novos produtos e serviços, e em seu imbricamento com a comunidade local/regional. Sua vocação histórica na realização de descobertas e inovações baseadas em atividades de pesquisa, especialmente naquelas mais recorrentes geradas após Segunda Guerra Mundial, contribuiu significativamente para o estabelecimento da orientação empreendedora na instituição. Vários produtos e serviços desenvolvidos com base nas atividades de pesquisa da LU alcançaram o mercado internacional, impulsionaram a melhoria da qualidade de vida e formaram as bases para novas empresas ou impeliram aquelas já existentes.

Estrategicamente instalada pelo governo sueco, na cidade de Lund, em 1666, como forma de fortalecimento do retomado território da Escânia, a LU desenvolveu uma trajetória estreitamente vinculada com seu entorno de atuação. A despeito de sua história secular e dos inúmeros vínculos com a comunidade local/regional, desenvolvidos durante sua história, esse envolvimento se reflete em diversos momentos e de formas variadas, evidenciando o foco em seu entorno de atuação, como defendido por Clark (1998).

Não obstante acumular séculos de história, os primeiros 200 anos da LU foram assinalados pelo lento crescimento de seu campus, especialmente em torno da histórica catedral da cidade. No entanto, nas últimas décadas, a universidade tem mudado significativamente sua rotina e sua organização interna, apesar de ter uma visão aparentemente conservadora (WESTLING, 2011).

As alterações se devem, em boa parte, à sua extensa trajetória de inovação, marcada por diversas descobertas realizadas por seus pesquisadores. Na área médica, dois grandes exemplos podem ser mencionados. O primeiro, capitaneado pelo cientista clínico Nils Alwall, professor de medicina interna na LU, foi a adoção do rim artificial utilizado na primeira hemodiálise realizada, em 1946, em um paciente com insuficiência renal. A máquina primitiva foi, posteriormente, aperfeiçoada e colocada em produção, tornando-se a base da empresa multibilionária Gambro (atual Baxter). O segundo feito histórico foi conduzido, em 1953, pelo especialista em coração Inge Edler e pelo físico Hellmuth Hertz, ambos professores na LU e que utilizaram, pela primeira vez, o ultrassom para o diagnóstico de doenças do coração. O uso do ultrassom difundiu-se amplamente e Hertz foi indicado para o Prêmio Nobel em física, no entanto não o obteve por razões diversas (WESTLING, 2011).

Além desses exemplos, várias outras inovações foram realizadas durante a trajetória da LU, as quais trouxeram melhorias à qualidade de vida ou contribuíram, de alguma forma, com a sociedade em geral, como a descoberta da intolerância à lactose (1963), a criação da tecnologia de jato de tinta para impressoras (1972), o método de tratamento de câncer a laser (1991), o desenvolvimento da tecnologia de reconhecimento facial (2004), o tratamento pré-eclâmpsia (2009), entre inúmeras outras. Desde 1999, a instituição investiu em mais de 80 empresas de pesquisa, as quais juntas têm gerado mais de 3,3 mil postos de trabalho e 100 milhões de euros em receita. Apenas em 2016, a instituição requereu 18 pedidos de patentes e constituiu 20 empresas, com participação acionária em seis delas (LU, 2019).

A despeito dessa trajetória de sucesso, o clima de cooperação entre a universidade e o mundo dos negócios nem sempre foi consenso. No final da década de 1960, havia atitudes hostis a essa relação, Educação em Revista | Belo Horizonte | v.37 | e20291 | 2021 
evidenciadas pelo comportamento hesitante de alguns professores e por críticas generalizadas envolvendo a universidade e as empresas. No entanto, na segunda metade dos anos 1970, a cooperação entre universidade e empresas havia aumentado através de vários caminhos. O clima mudou significativamente para uma relação natural, especialmente desde o início das atividades do parque tecnológico Ideon, no começo dos anos 1980 (FEHRMAN; WESTLING; BLOMQVIST, 2005).

No campo legal-regulatório, dois marcos foram importantes para tal mudança. O primeiro foi a reforma universitária realizada pelo governo da Suécia, em 1977. Ela estabelecia a democratização das formas de governança para as universidades, com descentralização do poder do governo e ampla disseminação das informações sobre as atividades de pesquisa e desenvolvimento, as experiências obtidas, o conhecimento acumulado e sua aplicação. Gradualmente, as universidades adotaram formas mais apropriadas de organização e de tomada de decisão (FEHRMAN; WESTLING; BLOMQVIST, 2005), o que, por um lado, outorgou-lhes mais responsabilidade e, por outro, permitiu maior diferenciação e liberdade na gestão universitária.

O segundo importante marco foi o regulamento da educação superior de 1997, realizado pelo governo sueco, o qual introduziu o termo "the third task", ao lado das atividades de ensino e pesquisa, como um rótulo para o dever de disseminação da informação e de interação com o mundo ao redor, envolvendo meio empresarial, administração pública, associações e organizações de todos os tipos. Isso representava o desejo da política de pesquisa da Suécia em relação à transferência de conhecimento das universidades para a sociedade de forma mais ampla (FEHRMAN; WESTLING; BLOMQVIST, 2005; STAAF, 2016).

A fim de aproveitar essas mudanças, a LU criou, em 1999, o Lund University Innovation System (LUIS), um escritório de inovação com o objetivo de gerar crescimento a partir das pesquisas da Universidade e assegurar a aplicação do conhecimento em benefício da sociedade. O papel do LUIS é estabelecer um elo entre a academia e a indústria, por meio da transferência de conhecimento e tecnologia da universidade para a indústria e o setor público. Além de explorar o conhecimento existente na Universidade, o LUIS também visa à compreensão das necessidades da sociedade e à conexão com as pessoas certas na universidade. Isso implica uma combinação entre expertise acadêmica, espírito empreendedor e experiência industrial (LU, 2017).

Logo após o início das atividades do LUIS, em 2001, a School of Economics and Management da LU criou o VentureLab, nascido como um projeto para apoiar os alunos empreendedores daquela Escola em direção à formação de novas empresas. A iniciativa tornou-se interessante e foi extrapolada para o restante dos alunos da LU. Atualmente, o VentureLab está vinculado ao LUIS e suas atividades atingem em torno de cinco mil estudantes a cada ano, em um ambiente interdisciplinar e criativo para o empreendedorismo, onde as ideias com melhor potencial seguem para o processo de incubação (LU, 2019).

Além dessas iniciativas próprias da LU, uma das principais ações institucionais de colaboração com parceiros externos, especialmente o município de Lund e as empresas, reside na constituição do parque tecnológico Ideon, em 1983, destacada por Kaiserfeld (2017). Ele se desenvolveu como alternativa para a crise regional instalada e, atualmente, abriga cerca de 400 empresas, como IKEA, Ericsson e Sony, e emprega em torno de nove mil pessoas. Parte da expansão do Ideon provém de pequenas empresas formadas para explorar os resultados de pesquisa da LU (FEHRMAN; WESTLING; BLOMQVIST, 2005).

"I think that one important part of this is the founding of the buildings that are just beside us here, the Ideon Science Park. I think that's one of the major, you know, important events which Lund University moved from a more traditional, I think, maybe not ivory tower but in that respect so to speak, [...] to think of research also being economically interesting, commercializing, and so on." (Interviewee 34)

\footnotetext{
"So, today I think it's about $25 \%$ of the companies here [Ideon] are ICT, IT industry, and there are more companies to account because of the heritage of Lund University and then another $25 \%$ are life science, but that's because of the heritage of AstraZeneca who was here before, not anymore, and that also linked to University and research [...]. Then, the other 50\% are spread in other areas here.” (Interviewee 32)
}

A proximidade com a LU tem sido fundamental para o sucesso do Ideon. Ao longo dos anos, 3/4 das empresas que o compõem têm algum tipo de ligação com a LU. Simultaneamente, o Ideon 
tem desempenhado relevante papel na história da LU, por meio da aproximação com as empresas e da contribuição para a busca ativa dessa aproximação (STAAF, 2016).

Além desse empreendimento, que resultou em um dos maiores parques tecnológicos da Europa (FEHRMAN; WESTLING; BLOMQVIST, 2005), a LU se engajou em diversas outras iniciativas que contribuíram para sua transformação interna e de seu entorno. Um exemplo que evidencia, mais recentemente, esse engajamento está na constituição do Medicon Village, em 2012, cuja formação foi desenvolvida segundo o modelo de hélice tríplice, capitaneada pela LU. Com atuação direta na busca de soluções para o número significativo de desempregados que adviria do fechamento das operações da AstraZeneca em Lund, a LU novamente agiu de forma colaborativa com o município e com as empresas para a formação de um novo parque tecnológico, agora voltado especificamente para a área das ciências da vida. No ano seguinte à fundação do Medicon Village, em 2013, a LU transferiu 200 de seus pesquisadores em câncer para o novo parque tecnológico (MEDICON VILLAGE, 2019) como mais uma demonstração de seu envolvimento com o entorno de atuação.

A ativa atuação da LU, no desenvolvimento de novos mecanismos alinhados à terceira missão acadêmica, está diretamente relacionada com a abordagem de Etzkowitz (2013a), notadamente no papel-chave desempenhado pela universidade na condução de esforços para a renovação regional, a exemplo do explorado por Benneworth et al. (2009) em seu trabalho sobre a influência da LU no fortalecimento do sistema regional de inovação da Escânia. Por meio de diversos vínculos estabelecidos com parceiros externos, a LU tem contribuído para a formação de inúmeras empresas baseadas na pesquisa acadêmica e participado ativamente na estruturação de novas organizações regionais, como o Ideon e o Medicon Village, como preconizado por Etzkowitz et al. (2000).

Os principais marcos que retratam o estabelecimento da orientação empreendedora na LU incluem o desenvolvimento de mecanismos internos e externos em uma variedade de estratégias, como sustentado por Grimaldi et al. (2011). Destaca-se a influência, na implementação da terceira missão acadêmica pela LU, das reformas universitárias realizadas pelo governo sueco, as quais oportunizaram o estabelecimento da própria direção estratégica, como preconizado por Clark (1998) e Etzkowitz (2013a), e, consequentemente, a transformação de seu perfil em direção a um modelo de universidade empreendedora.

Os diferentes movimentos realizados pela LU em direção a um modelo de universidade empreendedora são dotados de significativo enraizamento local/regional e/ou estão arraigados na própria trajetória institucional, o que encontra subsídio nos trabalhos de Nelles e Vorley (2010b), O’Shea et al. (2005), Philpott et al. (2011) e Stensaker e Benner (2013). A LU criou uma série de mecanismos internos, empresas associadas, parcerias e conexões externas para apoiar a estrutura industrial da Escânia e com ela se engajar. Assim, se formaram as bases para a transformação da LU, historicamente caracterizada como uma universidade humboldtiana clássica, porém, nas últimas décadas, remodelada em direção aos pressupostos de uma universidade empreendedora. Essa transformação incluiu diversas alterações internas que permitiram crescente envolvimento da LU com o desenvolvimento local e regional (BENNEWORTH et al., 2009). A partir da análise individual dos três casos pesquisados, a próxima subseção aborda, de forma sintética, a análise cruzada das universidades estudadas.

\section{TRÊS UNIVERSIDADES, DIFERENTES CAMINHOS E UMA DIREÇÃO}

A orientação empreendedora estabelecida pelas universidades pesquisadas possui significativa relação com a trajetória particular de cada instituição, o entorno de atuação e os elos desenvolvidos com parceiros externos. Nos três casos tratados, as trajetórias percorridas representaram diversificados acúmulos de recursos, o que resultou em transformações idiossincráticas nas instituições em direção a um modelo de universidade empreendedora, como abordado por Nelles e Vorley (2010b), O’Shea et al. (2005), Philpott et al. (2011) e Stensaker e Benner (2013).

No contexto das universidades brasileiras, a PUCRS e a PUC-Rio estão entre as mais tradicionais IES do país e revelam consistentes trajetórias, especialmente em relação à pesquisa e à pósgraduação. Constituídas na década de 1940, ambas as instituições deram início à pós-graduação na década de 1960, com pioneirismo em algumas áreas do conhecimento. O ímpeto inicial no desenvolvimento da pós-graduação foi maior na PUC-Rio, com o estabelecimento, ainda na década de 1960, de dez 
programas. Na PUCRS, o impulso ocorreu com o lançamento do programa "Mil mestres e doutores para o ano 2000", em 1988, e com a subsequente criação de inúmeros programas de pós-graduação.

Apesar dos diferentes tempos de impulso na pós-graduação, a PUCRS e a PUC-Rio alcançaram posição de destaque no cenário nacional, totalizando 24 e 28 programas, respectivamente, quase todos eles com conceito cinco ou superior. As trajetórias percorridas por ambas as instituições na pós-graduação, antecessoras ou simultâneas às transformações em direção a um modelo de universidade empreendedora, foram fundamentais para o desenvolvimento de projetos de pesquisa qualificados, capazes de captar recursos externos e estabelecer parcerias de desenvolvimento. Tais movimentos possibilitaram a consecução da terceira missão acadêmica, em especial no caso da PUC-Rio, devido a seu foco na realização de contratos de pesquisa.

No caso da LU, sua trajetória é secular e acumula cerca de 350 anos de história, caracterizando-a como uma das mais tradicionais universidades da Suécia. Por diversos fatos e influências que marcaram seu percurso, a LU desenvolveu uma trajetória vocacionada para a pesquisa, o que resultou em inúmeros produtos ou serviços que, especialmente após Segunda Guerra Mundial, contribuíram para a melhoria da qualidade de vida em geral. Sua vocação histórica na realização de descobertas e inovações baseadas em atividades de pesquisa mostrou-se como importante indicativo para a transformação da LU em direção à terceira missão acadêmica, tendo em vista sua aptidão para a pesquisa aplicada; a cooperação com empresas e governo; a formação de inúmeras empresas alicerçadas nos estudos acadêmicos.

As três universidades investigadas caracterizam-se pela articulação com seu entorno de atuação e participam ativamente no desenvolvimento econômico e social, o que está no cerne da terceira missão acadêmica, como abordado por Clark (1998), Etzkowitz (2013a, 2013b) e Philpott et al. (2011). Nos casos das IES brasileiras, tanto a PUCRS quanto a PUC-Rio são caracterizadas, desde suas fundações, pelo caráter comunitário, embora tenham sido legalmente reconhecidas como tal apenas em 2014. Apesar do reconhecimento tardio, ambas as instituições desenvolveram, ao longo do tempo, inúmeros vínculos com a comunidade local/regional, o que as distanciam largamente daquelas IES privadas com interesses puramente comerciais.

No caso da LU, o envolvimento com a comunidade local/regional evidencia-se por seu caráter público, especialmente na preocupação do governo sueco em relação à aproximação das universidades com a sociedade em geral, enfatizada desde a reforma da educação superior de 1977. À luz de Etzkowitz (2013a), o foco da LU em seu entorno de atuação reflete-se nos esforços por ela despendidos para a renovação regional e o fortalecimento do sistema de inovação da região da Escânia, notadamente no engajamento para a constituição e o desenvolvimento dos parques tecnológicos Ideon e Medicon Village, como detalhado no trabalho de Benneworth et al. (2009).

O envolvimento com o desenvolvimento econômico e social, que caracteriza as três universidades investigadas, realiza-se por meio de diversos elos estabelecidos com parceiros externos, os quais emolduram a orientação empreendedora de cada instituição. Isso se evidencia, por exemplo, nas inúmeras conexões entre a universidade e seu ambiente, como naquelas que formam o Tecnopuc na PUCRS, as unidades de pesquisa na PUC-Rio e as relações da LU com o Ideon e o Medicon Village. Na sequência, os apontamentos finais do estudo são apresentados.

\section{CONSIDERAÇÕES FINAIS}

As trajetórias desenvolvidas pelas universidades estudadas na implementação da terceira missão acadêmica foram antecedidas pelo foco nas atividades de pesquisa, o que forneceu as condições para a ampliação das interações universidade-empresa-governo. As evidências revelam que as universidades pesquisadas desenvolveram trajetórias baseadas nas atividades de pesquisa, as quais possuem vínculo de origem com a implementação da terceira missão acadêmica e exerceram significativa influência no incremento das relações universidade-indústria-governo.

Ao mesmo tempo, os casos estudados mostram significativa aderência a suas comunidades locais/regionais, por meio de diversos elos com atores externos e da contribuição para o desenvolvimento econômico e social, como sustentado por Clark (1998), Etzkowitz (2013a, 2013b) e Philpott et al. (2011). O enraizamento local/regional contribuiu para a formação de trajetórias particulares em direção a um modelo de universidade empreendedora, como mencionado por Nelles e Vorley 
(2010b), O’Shea et al. (2005), Philpott et al. (2011) e Stensaker e Benner (2013), o que refuta o caminho "one size fits all".

De um lado, a despeito dos diferentes contextos, a análise em questão revelou similaridades entre os casos pesquisados, o que reforça a importância de estudos comparativos em países distintos, como já realizado por Clark (1998, 2004), Etzkowitz (2003b), Guerrero et al. (2014) e Kalar e Antoncic (2015). De outro, a análise evidencia a importância das particularidades de cada caso, o que corrobora os trabalhos de Nelles e Vorley (2010b), O’Shea et al. (2005), Philpott et al. (2011) e Stensaker e Benner (2013).

Neste estudo, os três casos possuem trajetórias de sucesso no processo de transformação institucional em direção a um modelo de universidade empreendedora, bem como práticas exemplares na condução de esforços para o estabelecimento da orientação empreendedora no ambiente acadêmico. No entanto, casos de insucesso ou desprovidos de sustentação interna para a transformação institucional, especialmente aquela provocada por pressões isomórficas, podem revelar novas particularidades e/ou resultados distintos.

Ressalta-se também que as universidades no Brasil e na Suécia estão vinculadas a diferentes sistemas de educação e inovação em âmbito nacional. Eles produzem influências variadas em cada universidade e nos distintos contextos, especialmente naqueles de uma economia emergente e de uma economia avançada, nos quais se inserem o Brasil e a Suécia, respectivamente. No que pese tais diferenças, o foco desta pesquisa voltou-se para as transformações internas e os comportamentos estratégicos realizados pelas universidades estudadas em busca de um novo modelo organizacional, baseado nos preceitos da universidade empreendedora.

Por fim, a ascensão relativamente recente acerca da temática da universidade empreendedora, ocorrida em diversas partes do mundo, indica novas indagações e curiosidades, para melhor elucidá-la em diferentes contextos econômicos e sociais. Em consequência, há várias questões a respeito desse fenômeno que merecem investigação, ainda geram dúvidas ou suscitam novas discussões através de diferentes lentes e combinações teóricas, como por exemplo: a) o impacto no desenvolvimento regional, proporcionado pelo estabelecimento da orientação empreendedora no ambiente acadêmico, é tema que merece investigação, especialmente em regiões menos favorecidas em seus contextos ou desprovidas de infraestrutura avançada; b) o estudo de outras universidades que se orientam por um modelo de universidade empreendedora e que estão localizadas em diferentes contextos de economias emergentes permanece relevante. Como o desenvolvimento econômico e social está no centro da terceira missão acadêmica, a pesquisa em universidades de países emergentes reveste-se de significado, além de se constituir como campo empírico pouco explorado.

\section{RECONHECIMENTOS}

Pesquisa realizada com o apoio de bolsas CAPES-PROSUC e CAPES-PDSE.

\section{REFERÊNCIAS}

AFONSO, Oscar; MONTEIRO, Sara; THOMPSON, Maria. A growth model for the quadruple helix. Journal of Business Economics and Management, v. 13, n. 5, p. 849-865, 2012.

AGÊNCIA PUC-RIO DE INOVAÇÃO (AGI). AGI - Agência PUC-Rio de Inovação. 2016. 28 slides.

ALEXANDER, Allen T.; MILLER, Kristel; FIELDING, Sean. Open for business: Universities, entrepreneurial academics and open innovation. International Journal of Innovation Management, v. 19, n. 6, p. 1-21, 2015.

ALMEIDA, Mariza; MELLO, José Manoel Carvalho de; ETZKOWITZ, Henry. Social innovation in a developing country: Invention and diffusion of the Brazilian cooperative incubator. International Journal of Technology and Globalisation, v. 6, n. 3, p. 206-224, 2012. 
ASSOCIAÇÃO NACIONAL DE ENTIDADES PROMOTORAS DE EMPREENDIMENTOS INOVADORES (Anprotec). Prêmio Nacional - Vencedores. Brasília, 2019. Disponível em: $<$ http://anprotec.org.br/site/menu/premio-nacional/vencedores-do-premio-nacional/ >. Acessado em: 13 dez. 2019.

AUDY, Jorge Luis Nicolas; KNEBEL, Patricia. Tecnopuc: pessoas, criatividade e inovação. Porto Alegre: EDIPUCRS, 2015.

AZEVEDO, Carlos Eduardo Franco; OLIVEIRA, Leonel Gois Lima; GONZALEZ, Rafael Kuramoto; ABDALLA, Márcio Moutinho. A estratégia de triangulação: objetivos, possibilidades, limitações e proximidades com o pragmatismo. Anais do Encontro de Estudo e Pesquisa em Administração e Contabilidade, Brasília, DF, Brasil, 4, 2013.

BENNEWORTH, Paul; COENEN, Lars; MOODYSSON, Jerker; ASHEIM, Björn. Exploring the multiple roles of Lund University in strengthening Scania's regional innovation system: Towards institutional learning? European Planning Studies, v. 17, n. 11, p. 1645-1664, 2009.

BRAMWELL, Allison; WOLFE, David A. Universities and regional economic development: The entrepreneurial University of Waterloo. Research Policy, v. 37, n. 8, p. 1175-1187, 2008.

BRASIL. Lei $\mathbf{n}^{\mathbf{0}} \mathbf{1 2 . 8 8 1}$, de 12 de novembro de 2013. [It provides for the definition, qualification, prerogatives, and purposes of Community Higher Education Institutions, regulates the partnership agreement and provides other measures]. Disponível em: <http://portal.mec.gov.br/secretaria-deregulacao-e-supervisao-da-educacao-superior-seres/instituicoes-comunitarias>. Acessado em: 20 jan. 2020.

CARAYANNIS, Elias G.; CAMPBELL, David F. J. Mode 3 knowledge production in Quadruple Helix innovation systems: Twenty-first-century democracy, innovation, and entrepreneurship for development. New York: Springer, 2012.

CLARK, Burton R. Creating Entrepreneurial Universities: Organization Pathways of Transformation. United Kingdom: Emerald, 1998.

CLARK, Burton R. The entrepreneurial university: new foundations for collegiality, autonomy, and achievement. Higher Education Management, v. 13, n. 2, p. 9-24, 2001.

CLARK, Burton R. Sustaining change in universities: Continuities in case studies and concepts. Maidenhead, Berkshire, England: Society for Research into Higher Education \& Open University Press, 2004.

CLARK, Burton R. Pursuing the entrepreneurial university. In: AUDY, Jorge Luis Nicolas; MOROSINI, Marília Costa (Orgs.). Innovation and entrepreneurialism in the university. Porto Alegre: EDIPUCRS, 2006. p. 15-41.

COORDENAÇÃO DE APERFEIÇOAMENTO DE PESSOAL DE NÍVEL SUPERIOR (CAPES). Avaliação Quadrienal. Brasília, 2017. Disponível em: <http://avaliacaoquadrienal.capes.gov.br/>. Acessado em: 27 out. 2019.

EISENHARDT, Kathleen M. Building theories from case study research. Academy of Management Review, v. 14, n. 4, p. 532-550, 1989. 
EISENHARDT, Kathleen M.; GRAEBNER, Melissa E. Theory building from cases: opportunities and challenges. Academy of Management Journal, v. 50, n. 1, p. 25-32, 2007.

ETZKOWITZ, Henry. Entrepreneurial scientists and entrepreneurial universities in American academic science. Minerva, v. 21, n. 2-3, p. 198-233, 1983.

ETZKOWITZ, Henry. The norms of entrepreneurial science: cognitive effects of the new universityindustry linkages. Research Policy, v. 27, n. 8, p. 823-833, 1998.

ETZKOWITZ, Henry. Innovation in innovation: the Triple Helix of university-industry-government relations. Social Science Information, v. 42, n. 3, p. 293-337, $2003 \mathrm{a}$.

ETZKOWITZ, Henry. Research groups as 'quasi-firms': the invention of the entrepreneurial university. Research Policy, v. 32, n. 1, p. 109-121, 2003b.

ETZKOWITZ, Henry. Hélice tríplice: universidade-indústria-governo inovação em movimento. Porto Alegre: EDIPUCRS, 2013a.

ETZKOWITZ, Henry. Anatomy of the entrepreneurial university. Social Science Information, v. 52, n. 3, p. 486-511, 2013b.

ETZKOWITZ, Henry; KLOFSTEN, Magnus. The innovating region: toward a theory of knowledgebased regional development. R\&D Management, v. 35, n. 3, p. 243-255, 2005.

ETZKOWITZ, Henry; WEBSTER, Andrew; GEBHARDT, Christiane; TERRA, Branca Regina Cantisano. The future of the university and the university of the future: evolution of ivory tower to entrepreneurial paradigm. Research Policy, v. 29, n. 2, p. 313-330, 2000.

FEHRMAN, Carl; WESTLING, Håkan; BLOMQVIST, Göran. Lund and learning: The history of Lund University 1666-2004. Lund: Lund University, 2005.

FLICK, Uwe. An introduction to qualitative research. 4th ed. Thousand Oaks, CA: Sage Publications, 2009.

GERRING, John. Case study research: principles and practices. New York: Cambridge University Press, 2007.

GRIMALDI, Rosa; KENNEY, Martin; SIEGEL, Donald S.; WRIGHT, Mike. 30 years after Bayh-Dole: reassessing academic entrepreneurship. Research Policy, v. 40, n. 8, p. 1045-1057, 2011.

GUARANYS, Lúcia Radler dos. Interação universidade-empresa e a gestação de uma universidade empreendedora: A evolução da PUC-Rio. 2006. 342 f. Tese (Doutorado em Engenharia de Produção)Programa de Pós-Graduação de Engenharia, Universidade Federal do Rio de Janeiro (UFRJ), Rio de Janeiro, 2006.

GUERRERO, Maribel; URBANO, David; CUNNINGHAM, James; ORGAN, Damien. Entrepreneurial universities in two European regions: a case study comparison. Journal of Technology Transfer, v. 39, n. 3, p. 415-434, 2014.

GUERRERO, Maribel; CUNNINGHAM, James A.; URBANO, David. Economic impact of entrepreneurial universities' activities: an exploratory study of the United Kingdom. Research Policy, v. 44, n. 3, p. 748-764, 2015. 
HERRIOTT, Robert E.; FIRESTONE, William A. Multisite qualitative policy research: optimizing description and generalizability. Educational Researcher, v. 12, n. 2, p. 14-19, 1983.

KAISERFELD, Thomas. The money: commercial collaboration and innovation. In: BROBERG, Gunnar; DUNÉR, David (Eds.). Prepared for Both: Lund University and the surrounding world. Lund: Lund University, 2017. p. 253-287.

KALAR, Barbara; ANTONCIC, Bostjan. The entrepreneurial university, academic activities and technology and knowledge transfer in four European countries. Technovation, v. 36-37, p. 1-11, 2015.

LAZZARI, Ney José; KOEHNTOPP, Paulo Ivo; SCHMIDT, João Pedro. Apresentação. In: SCHMIDT, João Pedro. Instituições Comunitárias: instituições públicas não-estatais. Santa Cruz do Sul: EDUNISC, 2009. p. 11-13.

LUND UNIVERSITY (LU). About Lund University. Lund, 2019. Disponível em: <http://www.lunduniversity.lu.se/about/about-lund-university>. Acessado em: 23 nov. 2019.

LUND UNIVERSITY (LU). LU Innovation: 2016 | The year in brief. Lund, 2017. Disponível em: <http://www.innovation.lu.se/en/about-lu-innovation>. Acessado em: 07 jan. 2020.

MEDICON VILLAGE. About the Village - History. Lund, 2019. Disponível em: <https://www.mediconvillage.se/en/looking-ahead>. Acessado em: 18 dez. 2019.

MINISTÉRIO DE CIÊNCIA, TECNOLOGIA E INOVAÇÃO (MCTI). Parques \& Incubadoras para o Desenvolvimento do Brasil: Estudo de Práticas de Parques Tecnológicos e Incubadoras de Empresas. Brasília, 2015. 184p.

NELLES, Jen; VORLEY, Tim. Constructing an entrepreneurial architecture: an emergent framework for studying the contemporary university beyond the entrepreneurial turn. Innovative Higher Education, v. 35, n. 3, p. 161-176, 2010a.

NELLES, Jen; VORLEY, Tim. Entrepreneurial by design: theorizing the entrepreneurial transformation of contemporary universities. Industry \& Higher Education, v. 24, n. 3, p. 157-164, 2010b.

O'SHEA, Rory P.; ALLEN, Thomas J.; CHEVALIER, Arnauld; ROCHE, Frank. Entrepreneurial orientation, technology transfer and spinoff performance of U.S. universities. Research Policy, v. 34, n. 7, p. 994-1009, 2005.

PHILPOTT, Kevin; DOOLEY, Lawrence; O'REILLY, Caroline; LUPTON, Gary. The entrepreneurial university: examining the underlying academic tensions. Technovation, v. 31, n. 4, p. 161-170, 2011.

PONTIFÍCIA UNIVERSIDADE CATÓLICA DO RIO DE JANEIRO (PUC-Rio). Núcleo de Memória da PUC-Rio. PUC-Rio 70 anos. Rio de Janeiro: PUC-Rio, 2010.

PONTIFÍCIA UNIVERSIDADE CATÓLICA DO RIO DE JANEIRO (PUC-Rio). Núcleo de Memória da PUC-Rio. Anuário PUC-Rio 2015. Rio de Janeiro, 2016.

PONTIFÍCIA UNIVERSIDADE CATÓLICA DO RIO DE JANEIRO (PUC-Rio). Institucional. Rio de Janeiro, 2019. Disponível em: <http://www.puc-rio.br/index.html>. Acessado em: 20 nov. 2019.

PONTIFÍCIA UNIVERSIDADE CATÓLICA DO RIO GRANDE DO SUL (PUCRS). Institucional. Porto Alegre, 2019. Disponível em: <http://www.pucrs.br/>. Acessado em: 11 out. 2019. 
ROTHAERMEL, Frank T.; AGUNG, Shanti D.; JIANG, Lin. University entrepreneurship: a taxonomy of the literature. Industrial and Corporate Change, v. 16, n. 4, p. 691-791, 2007.

SECRETARIA DE REGULAÇÃO E SUPERVISÃO DA EDUCAÇÃO SUPERIOR DO MINISTÉRIO DA EDUCAÇÃO (Seres/MEC). Portaria $\mathbf{n}^{\mathbf{0}}$ 632, de 30 de outubro de 2014(a). Disponível em: <http://portal.mec.gov.br/secretaria-de-regulacao-e-supervisao-da-educacao-superiorseres/legislacao-e-atos-normativos>. Acessado em: 20 jan. 2020.

SECRETARIA DE REGULAÇÃO E SUPERVISÃO DA EDUCAÇÃO SUPERIOR DO MINISTÉRIO DA EDUCAÇÃO (Seres/MEC). Portaria $\mathbf{n}^{\circ}$ 679, de 12 de novembro de 2014(b). Disponível em: <http://portal.mec.gov.br/secretaria-de-regulacao-e-supervisao-da-educacao-superiorseres/legislacao-e-atos-normativos>. Acessado em: 10 jan. 2020.

SPOLIDORO, Roberto; AUDY, Jorge. Parque científico e tecnológico da PUCRS: TECNOPUC. Porto Alegre: EDIPUCRS, 2008.

STAAF, Björn Magnusson. The University of today 1977-2016. In: STAAF, Björn Magnusson; TERSMEDEN, Fredrik; FRANCKE, Petra (Eds.). Lund University over 350 years: history and stories. Lund: Lund University, 2016. p. 143-181.

STENSAKER, Bjørn; BENNER, Mats. Doomed to be entrepreneurial: institutional transformation or institutional lock-ins of 'new' universities? Minerva, v. 51, n. 4, p. 399-416, 2013.

TIJSSEN, Robert J. W. Universities and industrially relevant science: towards measurement models and indicators of entrepreneurial orientation. Research Policy, v. 35, n. 10, p. 1569-1585, 2006.

TIMES HIGHER EDUCATION (THE). World University Rankings 2018. Londres, 2017. Disponível em: <https://www.timeshighereducation.com/world-university-rankings/2018/worldranking\#!/page/0/length/25/sort_by/rank/sort_order/asc/cols/stats>. Acessado em: 26 out. 2019.

WESTLING, Håkan. Academic Lund - from old to new: A historical promenade. Malmö: Bild\&Media $\mathrm{AB}, 2011$.

WILLIAMS, Gareth; KITAEV, Igor. Overview of national policy contexts for entrepreneurialism in higher education institutions. Higher Education Management and Policy, v. 17, n. 3, p. 125-141, 2005.

YIN, Robert K. Estudo de caso: planejamento e métodos. 4. ed. Porto Alegre: Bookman, 2010.

Submetido: $24 / 04 / 2020$

Aprovado: 14/02/2021 